Антонова А. И.

A. I. Antonova

ЦЕЛИ УСТОЙЧИВОГО РАЗВИТИЯ ООН: РЕАЛИЗАЦИЯ В РАМКАХ СОЦИАЛЬНО-ЭКОНОМИЧЕСКОЙ ПОЛИТИКИ РОССИЙСКОЙ ФЕДЕРАЦИИ

\title{
UNITED NATIONS SUSTAINABLE DEVELOPMENT GOALS: IMPLEMENTATION WITHIN SOCIAL AND ECONOMIC POLICY OF THE RUSSIAN FEDERATION
}

Антонова Анна Ивановна - ассистент кафедры мировой экономики и таможенного дела Хабаровского государственного университета экономики и права (Россия, Хабаровск). E-mail: antonova0ai@gmail.com.

Ms. Anna I. Antonova - teaching assistant, World economy and customs affair department, Khabarovsk State University of Economics and Law (Russia, Khabarovsk). E-mail: antonova0ai@gmail.com.

Аннотация. В статье рассмотрены особенности долгосрочных целей в области устойчивого развития, утверждённые $\mathrm{OOH}$ в 2015 году, а также первые итоги их реализации в рамках социально-экономической политики Российской Федерации.

Summary. The article analyses characteristic property of long-term goals in the field of sustainable development, approved by the UN in 2015, as well as first results of their implementation in the social and economic policy of the Russian Federation.

Ключевые слова: цели устойчивого развития ООН, индикаторы устойчивого развития, социальноэкономическая политика.

Key words: the UN Sustainable Development Goals, sustainable development indicators, social and economic policy.

\section{УДК 338.268}

На сегодняшний день общество сталкивается с глобальными проблемами человечества, решение которых требует неотлагательных действий как на международном уровне, так и на уровне каждой отдельной экономики мира. Голод, экономическое неравенство, ограниченность и нерациональность использования природных ресурсов - все эти проблемы затрагивают каждую страну и являются препятствием для их дальнейшего развития. Всё это обусловило необходимость чёткого определения основ идеологии развития мирового сообщества на ближайшие десятилетия, которые нашли своё отражение в понятии «устойчивое развитие» и были закреплены в ряде документов (см. рис. 1).

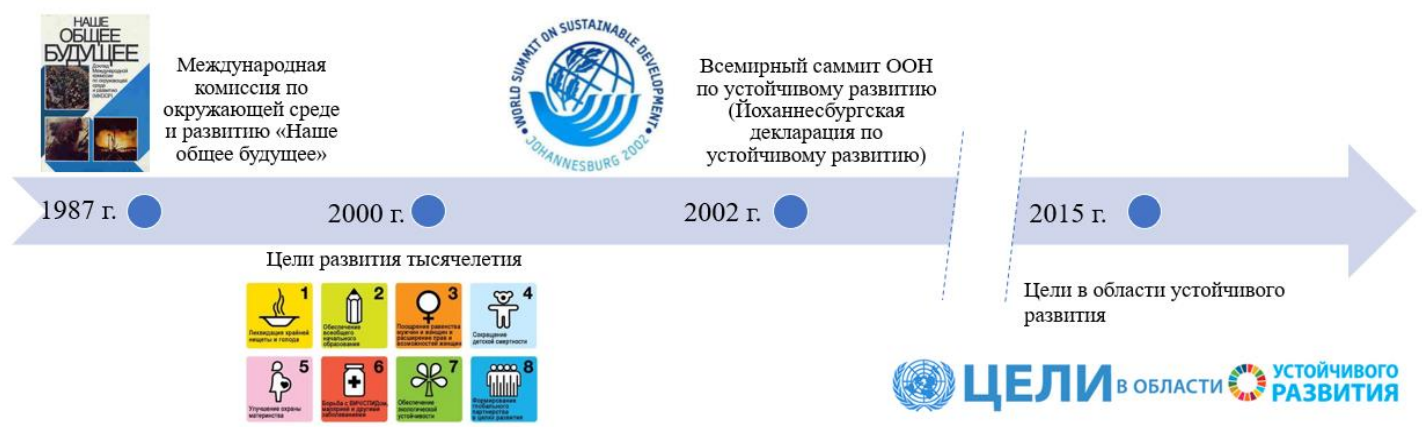

Рис. 1. Подходы к определению устойчивого развития 
Антонова А. И.

ЦЕЛИ УСТОЙЧИВОГО РАЗВИТИЯ ООН: РЕАЛИЗАЦИЯ В РАМКАХ СОЦИАЛЬНО-ЭКОНОМИЧЕСКОЙ ПОЛИТИКИ

РОССИЙСКОЙ ФЕДЕРАЦИИ

Определение устойчивого развития впервые прозвучало в 1987 году в докладе «Наше общее будущее» Международной комиссии по окружающей среде и развитию, где было установлено, что устойчивое развитие - это развитие, отвечающее потребностям нынешнего поколения без ущерба для возможностей будущих поколений удовлетворять их собственные потребности $[4,10]$.

Современные принципы устойчивого развития были сформулированы на саммите, проходившем 25-27 сентября 2015 г. в штаб-квартире Организации Объединённых Наций в Нью-Йорке: в рамках Генеральной Ассамблеи был принят итоговый документ ООН под названием «Преобразование нашего мира: повестка дня в целях устойчивого развития на период до 2030 года». Повестка дня, согласованная 193 государствами - членами ООН, состояла из Декларации, 17 целей в области устойчивого развития, 169 задач и свыше 230 индикаторов для их реализации [7].

Все цели в области устойчивого развития (далее - ЦУР) можно условно подразделить на 3 группы в соответствии с компонентами устойчивого развития: социальные, экологические и экономические. При этом ряд целей устойчивого развития является мультикомпонентным (см. табл. 1) [1, 34].

Таблица 1

Дифференциация целей устойчивого развития в соответствии с компонентами устойчивости

\begin{tabular}{|l|c|}
\hline \multicolumn{1}{|c|}{ Компоненты устойчивого развития } & Цели устойчивого развития ООН \\
\hline Экономические & $2,7,8,9,10,11,12,13,17$ \\
\hline Социальные & $1,2,3,4,5,10,11,12,16,17$ \\
\hline Экологические & $6,7,11,12,13,14,15,17$ \\
\hline
\end{tabular}

Несомненно, если говорить обо всём комплексе ЦУР, то Россия достигла уже многих из них. Тем не менее, в настоящее время наша страна сталкивается с рядом проблем. Как видно из табл. 2, в настоящее время некоторые из сформулированных целевых показателей всё ещё не были достигнуты Российской Федерацией.

Таблица 2

Выполнение целевых показателей целей в области устойчивого развития ООН в 2017 году

\begin{tabular}{|c|c|c|}
\hline Цель & Целевой показатель к 2030 году & Показатели России в 2017 году \\
\hline 8 & $\begin{array}{l}\text { - Ежегодный прирост ВВП - не менее } 7 \text { \% в год } \\
\text { в наименее развитых странах } \\
\text { - Экономический рост за счёт диверсификации } \\
\text { и модернизации }\end{array}$ & $\begin{array}{l}\text { - Рост номинального ВВП на } 3 \text { \% (в } 2017 \text { году } \\
\text { по сравнению с } 2016 \text { годом) } \\
\text { - } 63,2 \% \text { экспортных поступлений за счёт топ- } \\
\text { ливно-энергетических ресурсов }\end{array}$ \\
\hline 9 & $\begin{array}{l}\text { Расширить доступ малого бизнеса к недорогим } \\
\text { финансовым ресурсам }\end{array}$ & $\begin{array}{l}\text { Средний процент кредитования - } 13 \text { \% (США - } \\
3,5 \% \text {, Китай }-4,3 \%)\end{array}$ \\
\hline 10 & $\begin{array}{l}\text { Достичь и поддерживать рост доходов наиме- } \\
\text { нее обеспеченных } 40 \text { \% населения на уровне, } \\
\text { превышающем средний по стране }\end{array}$ & $\begin{array}{l}16 \% \text { населения с доходом ниже прожиточного } \\
\text { минимума, включая около } 50 \% \text { населения } \\
\text { с размером заработной платы ниже среднего }\end{array}$ \\
\hline 12 & $\begin{array}{l}\text { Добиться рационального освоения и эффектив- } \\
\text { ного использования природных ресурсов }\end{array}$ & 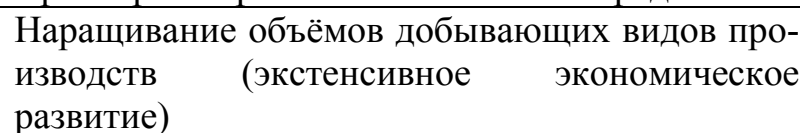 \\
\hline
\end{tabular}

В настоящее время экономику Российской Федерации сложно назвать ведущей экономикой мира ввиду ряда факторов, включая высокую зависимость экономики нашей страны от экспорта топливных ресурсов, низкой диверсификации экономики, слабым развитием отдалённых регионов. Сильнейшее отрицательное воздействие на Россию оказали санкции западных стран и резкое снижение цен на нефть, что в результате отбросило основные макроэкономические показатели на уровень 2009 года (см. рис. 2) [6]. 


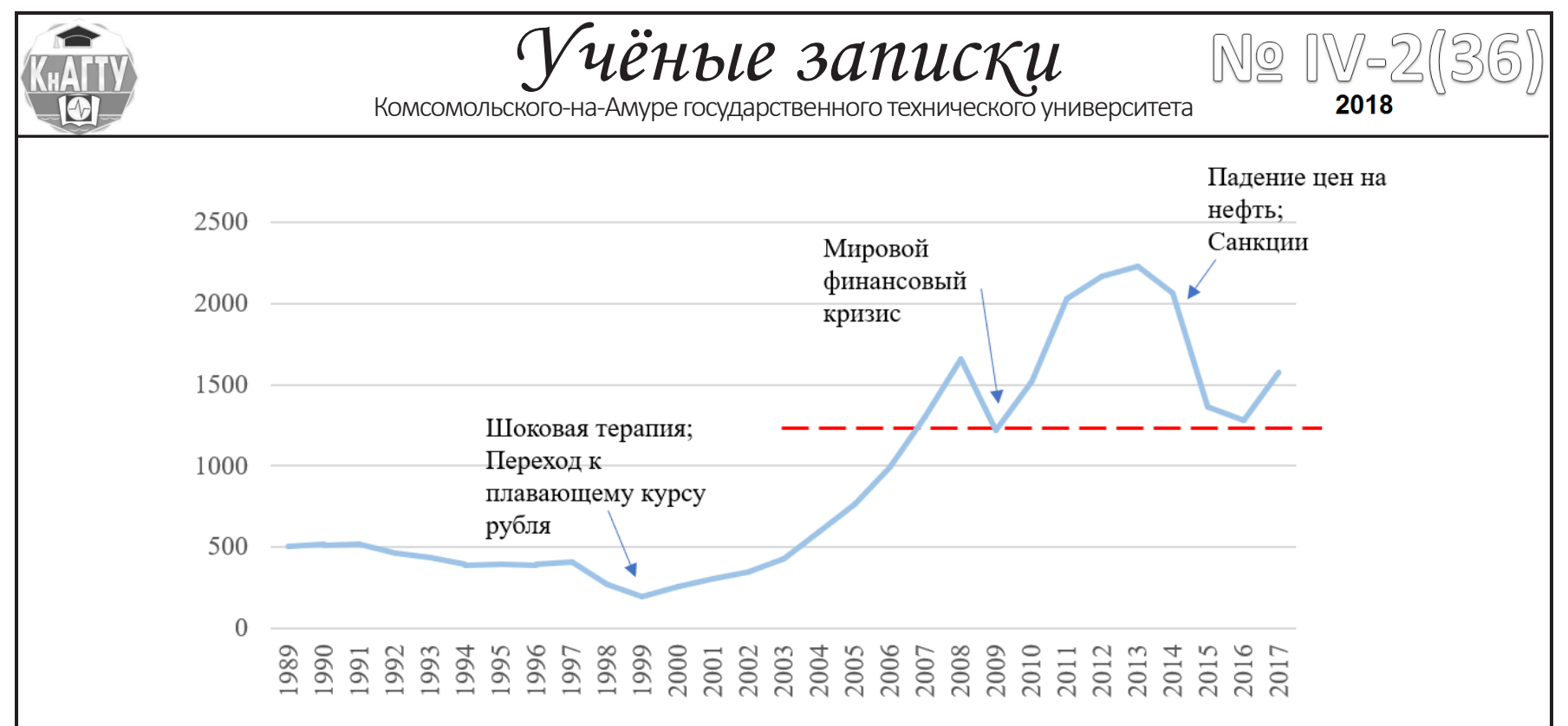

Рис. 2. Номинальный ВВП Российской Федерации в 1989-2017 гг., млрд долл. США

Уже сегодня предпринимаются попытки решения основных экономических проблем, стоящих на сегодняшний день перед Российской Федерацией: утверждаются разнообразные программы развития, в том числе адаптированные к ЦУР; увеличивается финансирование многих отраслей и т. д. В случае реализации так называемого «ускоренного восстановления» ожидается, что в период с 2017 по 2010 годы будут обеспечены условия для повышения предпринимательской деятельности, восстановится спрос на кредиты со стороны предпринимателей, включая малый и средний бизнес, а также увеличится приток прямых иностранных инвестиций в российскую экономику. Как следствие, российская экономика ориентировочно в 2019-2020 годах сможет вернуться к уровню 2014 года по уровню роста основных макроэкономических показателей [3, 18].

Кроме того, по показателю ВВП на душу населения по ППС прогнозируется, что Россия к 2030 году сможет сравняться с нынешним уровнем таких стран, как Италия и Польша - около 35 тыс. долл. на душу в год. При менее оптимистичном сценарии развития макроэкономических показателей Россия выйдет на уровень среднедушевого дохода по ППС лишь в размерах 29-30 тыс. долл. на душу населения, что равняется показателю таких стран, как Португалия, Словакия и Словения (см. рис. 3) [3, 20].

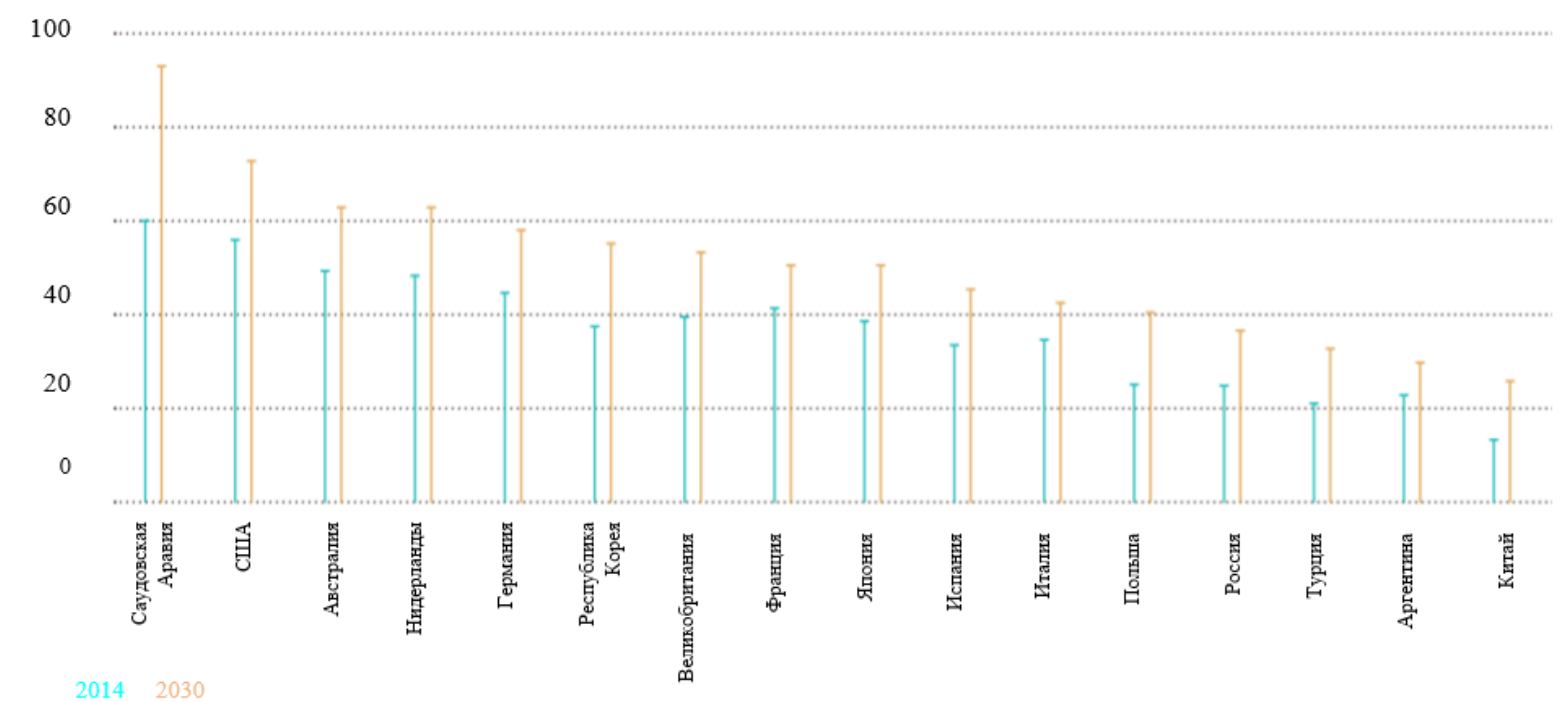

Рис. 3. Прогнозируемые значения ВВП на душу населения по ППС в тыс. долл. США 
Антонова А. И.

ЦЕЛИ УСТОЙЧИВОГО РАЗВИТИЯ ООН: РЕАЛИЗАЦИЯ В РАМКАХ СОЦИАЛЬНО-ЭКОНОМИЧЕСКОЙ ПОЛИТИКИ

РОССИЙСКОЙ ФЕДЕРАЦИИ

По данным аналитического центра Российской Федерации, в среднесрочной перспективе маловероятно, что бюджетные расходы на человеческий капитал значительно вырастут. В то же время не стоит ожидать увеличения государственных расходов на здравоохранение и образование ранее, чем к 2019 году. В случае умеренного восстановления экономики России (среднегодового роста ВВП на уровне 1,8-2,0 \%) бюджетные расходы на человеческий капитал достигнут к 2030 году 8 \% ВВП. Уровень частных и государственных инвестиций в человеческий капитал будет по-прежнему значительно уступать параметрам развитых стран.

Однако, несмотря на положительные прогнозы о дальнейшем экономическом развитии России, обсуждение путей и форм адаптации системы целей устойчивого развития ООН в соответствии с российскими потребностями и интересами нуждается в продолжении.

В настоящее время в качестве нормативно-правовой базы для разработки долгосрочного планирования служит Федеральный закон от 28 июня 2014 г. № 172-Ф3 «О стратегическом планировании в Российской Федерации», который в значительной мере определяет достижение стратегических целей и решение приоритетных задач государственной политики в сфере социальноэкономического развития страны и поддержания национальной безопасности. Являются обоснованными дополнения представленного выше перечня Стратегий устойчивого развития России, составленного в соответствии с Целями в области устойчивого развития ООН до 2030 года. $\mathrm{B}$ связи с участием России в ООН и вытекающими из этого международными обязательствами страны данная Стратегия может стать значимой частью системы стратегического планирования Российской Федерации, что в полной мере соответствует необходимости сбалансированного развития страны в экономической, социальной и экологической сферах.

\section{ЛИТЕРАТУРА}

1. Бобылев, С. Н. ООН: смена целей / С. Н. Бобылев, С. В. Соловьева // Мировая экономика и международные отношения. - 2016. - № 5. - С. 30-39.

2. Бобылев, С. Н. Цели устойчивого развития для будущего России / С. Н. Бобылев, С. В. Соловьева // Проблемы прогнозирования. - 2017. - № 3. - С. 26-33.

3. Доклад о человеческом развитии в Российской Федерации за 2016 год. Краткая версия / Под ред. С. Н. Бобылева и Л. М. Григорьева. - Аналитический центр при Правительстве Российской Федерации. - 2016. - 44 с.

4. Наше общее будущее: доклад Международной комиссии по окружающей среде и развитию (МКОСР) / Пер. с англ. С. А. Евтеева и Р. А. Перелета. - М.: Прогресс, 1989. - 21 с.

5. О стратегическом планировании в Российской Федерации: федер. закон от 28 июня 2014 г. № 172-Ф3 // Собрание законодательства РФ. - 2014. - № 26. - Ст. 3378.

6. GDP (current US \$) [Электронный ресурс]. - Режим доступа: https://data.worldbank.org/indicator/NY.GDP.MKTP.CD?end=2017\&locations=RU\&start=1960\&view= chart.

7. Transforming our world: the 2030 Agenda for Sustainable Development [Электронный ресурс] // Resolution adopted by the General Assembly on 25 September 2015. - Режим доступа: https://undocs.org/en/A/RES/70/1. 